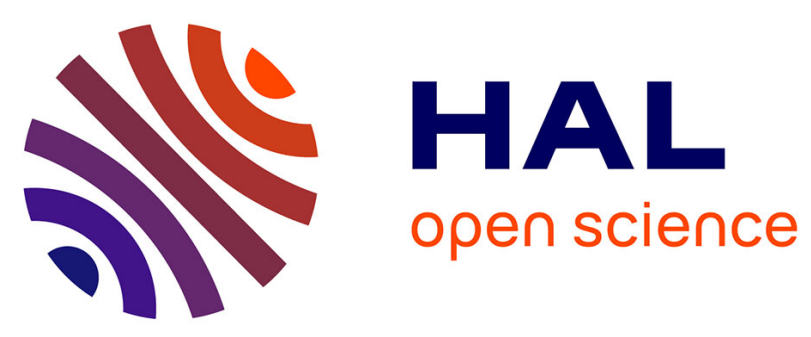

\title{
Entertaining as Simulation
}

François Recanati

\section{To cite this version:}

François Recanati. Entertaining as Simulation. Routledge. Force, Content and the Unity of the Proposition, 2021, 9780367561130. ijn_03470881

\section{HAL Id: ijn_03470881 \\ https://hal.science/ijn_03470881}

Submitted on 8 Dec 2021

HAL is a multi-disciplinary open access archive for the deposit and dissemination of scientific research documents, whether they are published or not. The documents may come from teaching and research institutions in France or abroad, or from public or private research centers.
L'archive ouverte pluridisciplinaire HAL, est destinée au dépôt et à la diffusion de documents scientifiques de niveau recherche, publiés ou non, émanant des établissements d'enseignement et de recherche français ou étrangers, des laboratoires publics ou privés. 


\title{
Entertaining as Simulation
}

\author{
François Recanati \\ Collège de France
}

Forthcoming in :

M. Schmitz, G. Mras (eds.)

Force, Content and the Unity of the Proposition

London: Routledge

\begin{abstract}
[Abstract] It is common to distinguish beween the content of a judgment, or the content of an assertion, and the (judicative/assertoric) force which is missing when the content is "merely entertained". This distinction, however, conflicts with the claim that propositional content is inherently judicative/assertoric (the judicative/assertoric component being what unifies the proposition). This chapter attempts to resolve the tension. All the cases in which a proposition is said to be merely entertained are shown to be cases in which, actually, a forceful act of assertion or judgment, or a forceful state of belief, is simulated. This applies not only to cases like fiction, irony, or supposition, but also to the cases in which a proposition is a part of a more complex proposition. The notion of simulation used here is the same one which "simulation theory" appeals to in connection with activities such as fiction (reading novels, watching movies, etc.), planning, mindreading, pretend play, and hypothetical reasoning.
\end{abstract}




\title{
Entertaining as Simulation
}

\begin{abstract}
Supposing is a more sophisticated operation than ingenuous thinking. (...) This point is worth making (..) because logicians and epistemologists sometimes assume, what I for a long time assumed, that entertaining a proposition is a more elementary or naïve performance than affirming that something is the case... This is a mistake. The concept of make-believe is of a higher-order than that of belief. (Gilbert Ryle, The Concept of Mind, p. 249-50)
\end{abstract}

\section{Unasserted propositions: three cases}

Frege famously argued that propositions (or, as he calls them, "thoughts") may be either asserted or unasserted. In the first of his three "Logical Investigations" he writes:

Two things must be distinguished in an assertoric sentence: the content, which it has in common with the corresponding [yes-no] question; and assertion. The former is the thought or at least contains the thought. So it is possible to express a thought without laying it down as true. The two things are so closely joined in an assertoric sentence that it is easy to overlook their separability. Consequently we distinguish:

(1) The grasp of a thought - thinking.

(2) The acknowledgment of the truth of a thought - the act of judgment.

(3) The manifestation of this judgment - assertion.

(“Thoughts", in Frege 1984: 355)

Assertion and judgment are both attitudinal or "forceful" elements, while the object or content of the attitude (that which is asserted or judged to be true - the thought) is supposed to be intrinsically forceless: since the attitudinal element comes in addition to the content it operates on, a thought may always be expressed, or entertained, without that additional element, that is, without force. That happens in two main types of case, according to Frege:

- When the assertoric sentence belongs to fiction (e.g. when it is uttered by an actor on the stage), or more generally when the speaker is not "serious" and does not subscribe to what he or she says.

- When the assertoric sentence at issue is a constituent of a longer sentence (e.g. when it is the antecedent of a conditional).

In both types of case, the sentence possesses "the assertoric sentence-form", yet it does not exhibit "the properly assertoric force" (Frege 1984: 356).

There is a third type of case in which a thought is expressed without being laid down as true. A thought may be expressed with another type of force than assertoric force. While the force of an assertoric sentence such as "It is raining" is bound to be assertoric force (unless it is deprived of force altogether, as in the two circumstances I have just mentioned), interrogative sentences such as "Is it raining?" express the same thought as their assertoric 
counterparts, but with the force of a question rather than that of an assertion. The thought is not asserted, but that does not mean that the utterance is forceless. As Frege writes,

An interrogative sentence and an assertoric one contain the same thought; but the assertoric sentence contains something else as well, namely assertion. The interrogative sentence contains something more too, namely a request. (Frege 1984: 355; emphasis mine)

The request Frege is talking about here is the "demand that we should either acknowledge the truth of a thought or reject it as false" ("Negation", in Frege 1984: 373; see the full excerpt below). Carrying such a request is the function of the interrogative sentence-form, just as assertion is the function of the assertoric sentence-form. In both cases the function may fail to be fulfilled. Like a fictitious assertoric sentence, an interrogative sentence may be uttered by an actor on stage, in which case the properly interrogative force will be missing. Stage questions are no more genuine questions than stage assertions are genuine assertions.

Imperative utterances too possess a kind of force distinct from assertoric force, and in that respect they are like interrogative sentences; but Frege denies that imperative sentences express thoughts. ${ }^{1}$ The content of a command, according to Frege, is not a thought, but a content of a different type. The reason for that is that thoughts are essentially true or false, while the question of truth does not arise for commands, wishes and requests (Frege 1984: 355). Strawson, who follows Frege here, calls the content of a command an "imperative" (Strawson 2000: 206). Propositions are true or false, he says, but imperatives, which indicate things to do, are not. Castañeda (1975) uses "practition" in more or less the same sense; he distinguishes the practition which is the content of a command from the proposition which is the content of an assertion.

One might respond that if questions are requests, as Frege holds, the question of truth shouldn't arise for them either. Indeed, a question such as "Is it raining?" is neither true nor false: only the answer to the question is. But precisely, Frege holds that a question is a request for an answer, and that is why the question of truth eventually arises :

A [yes-no] question contains a demand that we should either acknowledge the truth of a thought, or reject it as false. In order that we may meet this demand correctly, two things are requisite: first, the wording of the question must enable us to recognize without any doubt the thought that is referred to; second, this thought must not belong to fiction. (...) The answer to a question is an assertion based on a judgement. (Frege 1984: 373)

In other words a yes-no question expresses a thought, which may become the content of a speech act of assertion or denial; the question requests such a speech act from the hearer. It is because what is demanded is an answer - a true answer - that the question of truth arises for questions as much as it does for assertions, while it does not arise for commands, wishes and requests (unless they are requests for answers).

\footnotetext{
${ }^{1}$ Among contemporary theorists, many deny that questions have the same type of content as assertions, so they would reject Frege's claim that interrogative sentences express thoughts (a claim that doesn't apply to wh-questions anyway). According to their view, declarative sentences express thoughts/propositions, but neither interrogative nor imperative sentences do - they have a different type of semantic content.
} 
Table 1 summarizes Frege's view regarding the force and content of assertoric, interrogative and imperative sentences. All three types of sentence carry the relevant force only when uttered autonomously and seriously. ${ }^{2}$

\section{Force}

Assertoric sentence

Interrogative sentence

Imperative sentence
Assertion

Question

Command
Content

Thought

Thought

Imperative/Practition

Table 1: Frege on the force and content of different sentence types

\section{Supposing}

Let's turn to the case of someone who considers a proposition in order to determine whether it is true. The person might reason as follows:

(1) Suppose that $p$.

(2) Then $q$.

(3) But (we know that) not- $q$.

(4) Therefore, not- $p$.

This well-known pattern of reasoning consists in assuming something (the truth of a proposition) and inferring something from it. If what is inferred conflicts with what we know, it must be false, and we may conclude that the proposition from which it follows is itself false.

What is the status of the propositions that are respectively assumed (step 1) and inferred-under-the-assumption (step 2) with respect to the asserted/unasserted distinction? Neither the proposition that $p$ nor the proposition that $q$ are actually asserted by the reasoner. On the contrary, the reasoner asserts the negation of these propositions: not- $q$ (step 3) and not$p$ (step 4). Now we have seen that, for Frege, unasserted thoughts fall into three categories: thoughts that belong to fiction, thoughts that are constituents of more complex thoughts, and thoughts that are expressed with another type of force than assertoric force. To which category do the proposition that $p$ in (1) and the proposition that $q$ in (2) belong?

Let us start with the first option: fiction. Supposition is, in many ways, similar to fiction (Meinong 1983: 80-86). Fiction rests on pretense or make-believe (Searle 1975, Walton 1990, Kripke 2013). The author of a fictional story does as if he or she was telling truths - providing testimony (Lewis 1978). Likewise, the actor on stage does as if he was a certain character doing certain things, e.g. making assertions, asking questions, greeting people, etc.. None of this is real, however. As Frege says

\footnotetext{
${ }^{2}$ The autonomy requirement (the fact that, to carry any force, a sentence must be uttered in isolation) is too strong and it should be qualified, to make room for exceptions. As Meinong (1983: 31) points out, "there are plenty of dependent sentences that can be taken as expressions for judgments. Thus, if I say, 'the heat was so great that no one cared to leave the house at midday', then from the subordinate clause one may unhesitatingly infer the presence of the judgment, 'No one cared to leave the house at midday'." Frege himself acknowledges that "a subordinate clause may also contain an assertion" (Frege 1984: 356n).
} 
As stage thunder is only sham thunder and a stage fight only a sham fight, so stage assertion is only sham assertion. (Frege 1984: 356)

Now consider supposition, e.g. step 1 in the above reasoning. As William James writes, "Everyone knows the difference between (...) supposing a proposition and acquiescing in its truth" (James 1890: 288). In supposing, the reasoner does as if a certain proposition was true: he or she pretends to assert that proposition. ${ }^{3}$ That is very much like fiction. So the first step in the above reasoning features a fictitious assertion. Then, from the proposition fictitiously asserted at step 1, the reasoner infers something (step 2). Someone like Frege might object that one can make inferences only from premisses which one actually asserts - not from propositions which one only pretends to assert. But one can certainly pretend to derive consequences from a proposition which one pretends to assert. Indeed, the consequences in (2) are drawn "under the supposition", that is, in the scope of the pretense that the initial proposition is asserted. Therefore, just as the assertion in (1) is only a sham assertion, the inference in (2) is only a sham inference. ${ }^{4}$ On this view the only real assertions in the above reasoning occur at steps (3) and (4). (3) is an independent premiss which the reasoner actually asserts, and (4) is the conclusion of the reasoning. All the rest - the first two steps of the reasoning - is fiction, in a broad sense of the term.

How is the conclusion reached, and what role does the fiction play in the reasoning? From the fact that, having (fictitiously) asserted that $p$, one can (fictitiously) infer that $q$, it follows that $p$ implies $q$. This is an instance of pragmatic implication, codified in natural deduction as the rule of Conditional Introduction. ${ }^{5}$ This rule allows the reasoner to make an assumption, derive something from it, and conclude that the assumption in question entails the consequence in question. Conditional Introduction involves a "sub-proof" corresponding to the two-step pretense in the above reasoning. Even though the sub-proof rests on pretense, it yields genuine knowledge: that $p$ implies $q$. This piece of knowledge is exploited in the above reasoning: from the fact that $p$ implies $q$, plus the fact that not- $q$, one can infer that not$p$.

Frege, of course, would not accept that valid reasoning can rest on, or involve, fiction. As Dummett points out,

Not only does Frege not make use of supposition in formalizing logic, but his general account of inference rules out the possibility of taking supposition as a separate linguistic act at all. According to him, one can make inferences only from true premisses, and hence not from a mere hypothesis. (Dummett 1973: 308)

Frege would presumably formalize the above reasoning by construing the two initial steps, (1) and (2), as equivalent to the assertion of a conditional proposition. "Suppose that $p$; then $q$ " is thus treated as a notational variant of "If $p$, then $q$ " (Dummett 1973: 309-310; Currie 1987: 56). On that construal, the proposition that $p$ and the proposition that $q$ are unasserted

\footnotetext{
3 "Assuming, supposing, entertaining, toying with ideas, and considering suggestions are all ways of pretending to adopt schemes or theories" (Ryle 1949: 249).

4 "Inference from mere conjecture is not inference proper, for the machinery is put to some etiolated use, as is the machinery of assertion in a theatrical setting" (Currie 1987: 57).

${ }^{5}$ A pragmatic implication is an implication of an action (typically, of a speech act). Some are codified in logic and give rise to rules of inference. For example, if one has demonstrated $\phi$ without appealing to any empirical premiss, one can infer that $\phi$ holds necessarily: "Necessarily, $\phi$ " is something which the felicitous performance of the act of demonstrating that $\phi$ implies. See the discussion of "improper rules of inference" (a notion that traces back to Prawitz 1965) in Breckenridge and Magidor 2012, §2.2. In the case of Conditional Introduction, they say, "we seem to infer $\phi \rightarrow \psi$ from the fact that we have shown that $\psi$ follows from $\phi$ " (emphasis mine).
} 
because, at the level of logical form, they only occur as constituents in a more complex proposition which is asserted, namely, the conditional proposition. This is the second of the three options I listed in the beginning of this section.

The third option corresponds to what Dummett describes as "an account of the linguistic activity of giving a deductive argument which acknowledges the existence of a distinct linguistic act of supposition". Dummett represents the difference between such an approach and Frege's as follows:

According to an account of the former type, a deductive argument would consist of a sequence of linguistic acts of four different kinds: (1) assertions made without indication of the grounds for them; (2) assertions of thoughts as following from thoughts previously asserted (...); (3) statements of suppositions; and (4) expressions of thoughts as holding under given suppositions, and as following from thoughts previously registered as so holding (...). The sign for a supposition would of course be the word 'Suppose', and that for an act of kind (2) or (4) a word like 'Therefore', 'Hence', 'So', etc. However, on Frege's account, which dispenses with supposition as a separate linguistic act, an argument consists of a sequence of utterances of two kinds only: plain assertions (the premisses), as in (1) above; and assertions which are expressed as following from earlier assertions, words like 'therefore' being used to convey the force of this special kind of assertion. (Dummett 1973: 313-314)

Gentzen's way of formalizing inference ${ }^{6}$ corresponds to the former type of account. It

leave[s] a place for the introduction of hypotheses in a manner analogous to that in which, in everyday reasoning, we say, 'Suppose...': e.g. 'Suppose $\mathrm{m} / \mathrm{n}$ is a square root of 2'. We require no warrant for introducing any new hypothesis, and we reason from it in accordance with just the same rules as those governing inferences from premisses which we assert outright: the point of the procedure being that, from the fact that certain consequences follow from some hypothesis, we can draw a conclusion which no longer depends on that hypothesis. (...) In supposition, a thought is expressed but not asserted: 'Suppose...' must be taken as a sign of the force (in our sense) with which the sentence is uttered. (Certainly it is not logically an imperative: I could, having said, 'Think of a number', ask 'Have you done so yet?', but it would be a joke if I asked that question having said, 'Suppose the witness is telling the truth'.) (Dummett 1973: 309)

So the content of the linguistic act of supposition is a thought, but to suppose something is not to assert it. Suppositions, on this view, are in the same ballpark as yes-no questions understood à la Frege: their content is a thought but their force is non-assertoric.

Until now I have presented the first option (treating supposition as an instance of fiction) and the third option (treating supposing as a non-assertoric speech act in the same ballpark as questioning) as two competing accounts of the phenomenon, alongside the second option (treating "suppose that $p$ " as equivalent to "if $p$ "). In the next section, however, I will show that the first and the third option can be integrated into a single account. Supposition, I will argue, $i$ s an instance of fiction, in a broad sense: to suppose is to pretend to assert. But supposition construed as fictitious assertion is not the expression of a proposition without any force, the proposition in question being "merely entertained" (as Frege seems to hold). It is a

\footnotetext{
${ }^{6}$ See Gentzen 1969.
} 
speech act endowed with a force of its own, albeit one that is parasitic upon a more basic kind of force.

\section{Parasitic force}

If Frege's analysis is on the right lines, interrogative force is parasitic with respect to assertion, in the sense that a yes-no interrogative presents or evokes a potential assertion, and asks the hearer to embrace it ('yes') or to disavow it ('no'). ${ }^{7} \mathrm{~A}$ force is parasitic whenever its specification requires reference to some other, more basic type of force, ${ }^{8}$ according to the following schema (which uses Searle's 1969 symbolism for speech acts):

$\mathrm{F}_{2}(p)=f\left(\mathrm{~F}_{1}(p)\right)$

Here " $F_{1}$ " is a basic or primary force (e.g. assertion); " $p$ " is the content the force operates on (e.g. the thought that it is raining); and " $f$ " is a function mapping the speech act $\mathbf{F}_{\mathbf{1}}(\boldsymbol{p})$ to some other speech act $\mathbf{F}_{2}(\boldsymbol{p})$ (e.g. the interrogative function $f_{\text {? }}$ mapping the assertion that it is raining to the demand that the hearer should embrace or disavow the assertion that it is raining). ${ }^{9}$

The Fregean analysis of yes-no interrogatives is controversial, as I pointed out in footnote 1 . If one rejects it, it is likely that one will also reject the idea that interrogative force is parasitic on assertive force. ${ }^{10}$ But the notion of parasitic force is interesting in its own right, and it applies beyond the case of questions. Thus I take it as more or less obvious that the force of a fictitious assertion (e.g. an assertion made by an actor on the stage) is parasitic on that of a regular assertion. ${ }^{11}$ The notion of parasitic force is implicit in the following passage in which Dummett seeks to clarify the status of the actions performed by an actor on the stage:

Of the actions performed by a character in a play, the actor who takes that role for the most part really does those which are not conventional (...): for example, the actor really shakes hands with someone. But if some action is considered under a description which applies to an action only in virtue of the existence of some convention, we do not say that the actor really does it: for example, in shaking hands

\footnotetext{
${ }^{7}$ Disavowal itself, for Frege, amounts to assertion of the negation of the thought at issue.

${ }^{8}$ The distinction between parasitic and basic (or primary) force corresponds to Ryle's distinction "between higher order tasks and lower order tasks, and between higher order performances and lower order performances, meaning by a 'higher-order' task, one the description of which incorporates the notion of another task of a less complex description" (Ryle 1949: 248). The same notion of a higher order act is used by Schmitz (2019, forthcoming) in dealing both with questions and with fictitious assertions (see below).

${ }^{9}$ Can the interrogative function apply to non-assertoric speech acts as well as to assertions? Can it, for example, map a directive (e.g. the suggestion to go for a walk) to the demand that the hearer should embrace or disavow that directive? According to Schmitz (2019, forthcoming), it can. Schmitz construes questions as higher-level acts that can operate on assertions (yielding "theoretical questions") but also on directive speech acts (yielding “practical questions”): “There are (...) practical questions like (...) 'Go for a walk?' or 'Close the door?'. (...) In contradistinction to theoretical questions, which are reported through whether + finite clauses, practical questions are reported through whether + to-clauses, e.g.: 'She asked whether the door is closed', 'She asked whether to close the door'. This pattern of reports further supports the analysis of questions as higher-level acts that can operate on theoretical or practical acts" (Schmitz 2019: 124-5).

${ }^{10}$ Still, the claim that interrogative force is parasitic can be maintained even if one holds that the semantic content of an interrogative sentence is not a proposition but e.g. a set of propositions. Thus Schmitz takes his analysis of theoretical questions as higher-level acts performed on assertions to be "consonant with (...) the ideas familiar from formal semantic accounts of questions that they have answerhood conditions and (sets of) propositions as their denotation rather than truth values" (Schmitz 2019: 125).

${ }^{11}$ See Recanati (forthcoming $a$ ). As I already mentioned, questions and fictitious assertions are both higher-level acts according to Schmitz (2019, forthcoming).
} 
with someone, the actor does not really greet him. This is not, however, because the actor is like someone from another culture who is not observing the convention: rather, it is because he is performing the conventional action in a context which is governed by a further convention - that of dramatic representation. This is indeed a convention - a special language-game (...). But it is not a language-game on the same level as, e.g., those of asking questions and giving commands. It is a convention which governs all the actions, conventional as well as non-conventional, which the actor performs within the context of the play, and endows them with a particular significance: and it does this to the conventional actions in virtue of the conventions which ordinarily govern them. Not any old way of shaking hands will do: the actor must shake hands in the way which, in the absence of any context governed by a special convention, would constitute a greeting. (Dummett 1973: 310-11; emphasis mine)

In Dummett's example the basic act is that of greeting the adressee, an act which is conventionally performed by shaking hands with her. The actor on stage "goes through the motions" of greeting, by shaking the adressee's hands, but does not actually greet her. The conventional significance of the actor's behavior is modified because of the special context it occurs in. The theatrical context endows that behavior with a new significance: instead of greeting the person in front of him (the other actor), the actor who shakes hands with her simulates greeting her. As Frege writes, "it is only acting, only fiction" (Frege 1984: 356). But this act of simulated-greeting is not on the same level as the act of greeting which is normally performed by shaking someone's hands. What one does when one shakes hands in a theatrical context is a function of what one does when one shakes hands in a normal context. If (as is actually the case) one normally greets someone by shaking their hands, then the same behavior in a theatrical context amounts to simulated greeting. In general, what one does on stage by behaving in a certain way is a function of what one does off-stage when behaving in that way. Theatrical simulation thus generates theatrical acts (e.g. playing the part of someone who greets) which are parasitic on the acts (e.g. greeting) which the actor simulates.

This analysis works for assertion as much as it does for greeting: the actor who says that $p$ on stage simulates the ordinary act of asserting that $p$, but actually performs the theatrical act of simulating that assertion (playing the part of someone who asserts that $p$ ). The parasitic force schema applies:

$\mathrm{F}_{2}(p)=f\left(\mathrm{~F}_{1}(p)\right)$

Here " $F_{1}$ " is, again, the primary force of assertion; " $p$ " is the content the force operates on (the proposition whose assertion is simulated); and " $f$ " now is the simulative function $f_{s}$ mapping the speech act $\mathbf{F}_{1}(\boldsymbol{p})$ of asserting that $p$ to the parasitic speech act $\mathbf{F}_{2}(\boldsymbol{p})$ of simulating the assertion that $p$. The actor who says that $p$ on stage thus expresses the proposition that $p$ with the parasitic force of a simulated assertion.

The same analysis applies to supposition - this is what makes it similar to fiction. The reasoner who makes a supposition simulates the assertion of a certain proposition. The act which is actually performed, namely supposing, is a function of the act which is simulated, namely asserting. Thus construed, supposition is not on the same level as assertion, but is parasitic on it. The drawing of inferences from a hypothesis (second stage of the reasoning discussed in section 2) also falls within the scope of a simulation: from the supposition that $p$ one does not really infer that $q$ (for that would entail asserting that $q$ ), but one simulates 
inferring that $q .{ }^{12}$ Here the simulation function $f_{s}$ applies not to the act of asserting outright (as in the first stage of the reasoning) but to the act of inferring. If, as Dummett suggests, inferring is a special kind of assertion (assertion made on certain grounds), then simulated inference is a special kind of simulated assertion. But the simulation function $f_{s}$ can apply to non-assertoric speech acts as well. ${ }^{13}$ Applied to the acts of questioning or commanding, it gives rise to the parasitic acts performed by the actor when he simulates questioning or commanding on the stage.

\section{Is "mere entertaining” possible?}

Remember Frege's distinction between grasping or entertaining a thought, and asserting it or judging it to be true. If you say "If $p$ then $q$ ", you assert the whole conditional, but you do not assert the constituent propositions, which are merely expressed/entertained in the course of asserting the conditional. Likewise, the actor on the stage who utters an assertoric sentence does not really assert the proposition it expresses, nor does the reasoner who makes a supposition. These propositions are "merely entertained". Another standard example involves an ironical or sarcastic speaker. If I say "John is a fine friend" after he has blatantly betrayed me, I express the thought that John is a fine friend, without really asserting it - on the contrary, the point of the utterance it to emphasize how untrue that proposition is.

In the case of the actor and the reasoner, I suggested an alternative construal using the notion of parasitic force: rather than being forceless, as the notion of mere entertaining implies, the speech act performed by the actor or by the reasoner is construed as the simulation of the (forceful) act of asserting the relevant proposition. To bring that option into the picture we need a three-fold (rather than twofold) distinction between
A. Merely entertaining/expressing a proposition
B. Asserting that proposition
C. Simulating the assertion of that proposition

Dummett famously criticized Frege for not distinguishing $\mathrm{C}$ from $\mathrm{A}$ in the case of the actor:

The reason [the actor] is not making assertions is not that he is doing less than that merely expressing thoughts, say — but that he is doing more than that — he is acting the making of assertions. What constitutes his doing this is his uttering the assertoric sentence (...) in a context which determines the significance of everything he does in that context — on the stage in a theatre at an announced time. (Dummett 1973: 311)

The case of irony is very similar to the case of the actor. It is nowadays widely accepted that the ironical speaker stages an assertion which he does not endorse but, on the contrary, attempts to ridicule by displaying it in a context that shows how inappropriate it would be. Irony, on the account put forward in the early eighties by theorists such as Sperber and Wilson (1981), Ducrot (1984), and Clark and Gerrig (1984), is a matter of echoing a real

\footnotetext{
12 "Inference from assumptions (...) is mere simulation; as stage assertion is a simulation of assertion" (Currie 1987: 56-57). "We can regard supposing A as a simulated or offline analogue of receiving the new information A, and developing the supposition as a simulated or offline analogue of updating one's knowledge and beliefs on the new information" (Williamson 2020: 26).

${ }^{13}$ See footnote 9 for the analogous claim that the interrogative function $f_{\text {? }}$ can operate on non-assertoric speech acts as well as on assertions.
} 
or potential assertion, or pretending to assert something which one only makes as if to say. ${ }^{14}$ The phrase "make as if to say" is due to Paul Grice. As he points out,

To be ironical is, among other things, to pretend (as the etymology suggests), and while one wants the pretense to be recognized as such, to announce it as a pretense would spoil the effect. (Grice 1989: 54)

Irony thus belongs to the category of staged communicative acts, which also includes teasing, overstatements, understatements, and rhetorical questions (Clark 1996: 368-378). All these speech acts are parasitic and involve simulation.

Now what would be a genuine case of merely expressing a proposition (option A), that is, expressing a proposition without either asserting it (option B) or even simulating asserting that proposition (option C)? The only obvious candidates are the cases in which a proposition is used as a building block in constructing a more complex proposition which the speaker asserts (or pretends to assert). In what Frege calls "compound thoughts", a category that includes conditional propositions, disjunctive propositions, etc., the thoughts that are constituents of the compound are merely expressed. Dummett, who argues that fictional thoughts are not merely expressed/entertained but expressed/entertained with the force of a simulated assertion, does not extend that view to the propositions expressed by sentences used as constituents of more complex sentences. In such cases, he says,

The assertoric force applies only to the complete sentence taken as a whole. Its constituent clauses are not used, or taken to be used, to make assertions of their own. (Dummett 1973: 304)

Just as assertion only works at the level of complete, autonomous sentences, simulated assertion also works at that level. Sentences which are constituents of more complex sentences are not uttered with any kind of illocutionary force, whether parasitic or not. The propositions such sentences express are merely entertained (option A). Such is the classic Fregean position regarding sentences embedded within more complex sentences, a position which Dummett fully endorses.

But there is an alternative view, which denies that any proposition can be "merely entertained". In his work on (or, rather, against) the force-content distinction, Peter Hanks has argued that propositions are intrinsically forceful (not forceless, as on the Fregean picture). ${ }^{15}$ What secures the unity of a singular proposition, e.g. the proposition that Tom is bald, is the fact that the property (baldness) is predicated of the subject (Tom). Now to predicate a property of some individual is to take that individual to have that property. As Hanks puts it, "acts of predication are judgmental or assertoric in character, and they commit the speaker to things being the way they are represented to be in the act of predication" (Hanks 2019:

1385). So predication, which secures the unity of the proposition by appropriately combining subject and predicate, has an intrinsically judgmental or assertoric character. As a result there is no such thing as mere entertaining: without the judgmental/assertoric component inherent in predication, there would be no proposition in the first place. ${ }^{16}$

\footnotetext{
${ }^{14}$ See also Recanati (1987: 233-35). Sperber and Wilson and Clark and Gerrig criticize their respective accounts of irony (the "echoic" account and the "pretense" account) as if they were very different, but the differences seem to me a matter of emphasis and details rather than anything substantial. See Currie (2006) and Wilson and Sperber (2012, ch. 6) for discussion.

${ }^{15}$ See Hanks (2007), (2011), (2015).

${ }^{16}$ Commenting on Meinong's theory of assumptions, X. de Donato Rodriguez writes: "mental acts involving propositions require, if Meinong is right, the activity of a mental attitude and not the mere passivity of a representation" (Donato Rodriguez 2016: 153). The activity in question need not be belief: it may be simulated
} 
If option A, mere entertaining, is thus ruled out on principled grounds, what is going on when a proposition is a proper part of another, as in disjunctions or conditionals? Can we extend to such cases the idea of simulated assertion (option C)? In the case of conditionals, that would, in effect, reverse the Fregean move mentioned earlier. Instead of reducing "Suppose that $p$; then $q$ " to "If $p$, then $q$ ", we would take a conditional sentence "If $p$ then $q$ " to invite the hearer to suppose (i.e. to simulate the judgment) that $p$ and to realize that, under that supposition, it follows that $q$. (This approach to conditionals is implicit in the so-called Ramsey test.) A similar approach is popular in the case of negation: many theorists, starting with Sigwart (1904: 150ff) and (Bergson 1907: 311ff), have argued that a negative sentence evokes or stages (i.e. simulates) the assertion of the positive sentence that is negated.

Whatever one thinks of these familiar suggestions for handling conditionals or negation, they only apply to particular cases. What is needed, however, is a theory of compound sentences that systematically appeals to the idea that the assertion of a constituent proposition is simulated in the course of grasping the complex proposition of which it is a part. Such a theory, gestured at in my articles on force cancellation (Recanati 2019, forthcoming $b),{ }^{17}$ is what I am now going to present.

\section{Understanding as a form of acceptance}

In his Principles of Psychology, William James briefly presents and defends a view he ascribes to Spinoza. According to that view, which stands opposite to Frege's, to entertain a proposition is to believe it, to a minimal extent at least: it is to consider it as true. It is, of course, possible to doubt a proposition which one entertains, but Spinoza explains this phenomenon by saying that in that sort of case the mind assents more strongly to some other proposition which rules out the truth of the first one. The mind's assent to the first proposition is thus overruled by its acceptance of the other proposition. In that situation, Spinoza says, the belief in the first proposition may vanish, having been dislodged by the contrary belief, but it may also persist as a prima facie belief, or appearance, which we know to be false (as when it seems to us that the sun rises in the sky). ${ }^{18}$ Such appearances command a minimal degree of assent, without which the proposition could not even be entertained. As James concludes:

All propositions (...) are believed through the very fact of being conceived, unless they clash with other propositions believed at the same time. (James 1890: 290)

The sort of cases that Spinoza and James are concerned with are cases in which the subject "conceives" something, e.g. entertains a proposition. Even if the subject eventually rejects that proposition, entertaining or conceiving involves a form of primitive acceptance: the state of affairs which would make the proposition true is represented as holding. On this view also, there is no "forceless" or "mere" entertaining.

The Spinozist picture advertised by James in passing has been revived by a psychologist, Daniel Gilbert, in his work on language understanding. Gilbert argues against

belief, i.e. "provisionally accepting a state of affairs as factual (or making as if the proposition at issue is true)" (id.).

${ }^{17}$ Hanks says that, when a proposition is a proper part of another, as in disjunctions or conditionals, the assertion or judgemental component that is constitutive of the proposition is "cancelled", just as it would be cancelled if the proposition was expressed by an actor on the stage. On this view there is no mere entertaining, only cancelled assertion. The notion of cancelled assertion is notoriously difficult to interpret, however, and raises what many commentators take to be insuperable problems (Reiland 2013, Hom and Schwartz 2013). In Recanati (2019) I argue that the best way to make sense of the notion of cancelled assertion is to understand it as simulated assertion. See also Recanati (forthcoming $b$ ).

${ }^{18}$ Spinoza, Ethics, IV, Scholium of proposition 1. 
the traditional division between comprehending a proposition and believing it (Gilbert 1991). His argument proceeds in a two steps. The first step is empirical: he shows that acceptance and rejection are fundamentally asymmetric - they are not on a par. Acceptance (belief) is psychologically more basic than rejection (disbelief). The rejection of a proposition one comprehends occurs subsequent to, and more effortfully than, its acceptance, which is the default attitude. Default acceptance can be overriden if there are reasons to doubt the proposition, but this comes at a later stage and is more resource-consuming. Gilbert cites various studies showing that subjects who are exposed to doubtful propositions while being resource-depleted (e.g. through attending to an irrelevant stimulus) tend to accept these propositions which they would not normally believe. He then asks the question:

Why should [resource-depletion] necessarily engender acceptance? Indeed, if rejection efforts were to follow on the heels of "mere" comprehension (i.e., representation of meaning without acceptance), then the disabling of these efforts should leave the person without a belief of any sort. Such a person should understand what he or she has heard, but should not be particularly inclined toward or against it. (Gilbert 1991: 111)

The second step of Gilbert's argument is conceptual and it provides a response to his own question. It is well established in the philosophy of language that to understand a proposition is to know what the world would be like if it were true. Much of contemporary semantics is based upon that Wittgensteinian idea, an idea that has penetrated psychology too: Gilbert cites Johnson-Laird who noted that to comprehend a proposition one must "imagine how the world should be granted its truth" (Johnson-Laird 1986: 116), and Rips and Marcus who claim that the comprehension of a sentence involves "creating a temporary context in which the sentence is true" (Rips and Marcus 1977: 192). From that familiar idea, Gilbert draws the conclusion that acceptance is not merely more basic than rejection, but it is actually constitutive of understanding, as Spinoza held. The rejection of an idea occurs subsequent to, and more effortfully than, its acceptance, because acceptance is constitutive of the process of grasping the idea. Rejecting an idea or proposition presupposes grasping it; but to grasp a proposition is to accept it temporarily, to represent the situation it describes as holding. Hence the asymmetry between acceptance and rejection: acceptance is intrinsic to understanding, inseparable from it, while rejection presupposes understanding.

Of course, the preliminary form of acceptance that goes along with understanding can be cancelled as soon as understanding has taken place. Gilbert therefore distinguishes what we might call basic acceptance (an aspect of understanding) and all-things-considered acceptance which is a later achievement on a par with rejection. Thanks to that distinction between levels, an apparently paradoxical consequence of Gilbert's Spinozist view turns out to be unproblematic: disbelieving a proposition (rejecting it as untrue) involves believing it (at the "basic" level). As Gilbert puts it:

Because denials require the initial comprehension of that which is being denied and because Spinozan comprehension always entails acceptance of that which is comprehended, then a Spinozan listener who comprehends a denial should momentarily believe the very state of affairs that he or she is being instructed not to believe. (Gilbert 1991: 113)

This remarks about denial is interesting because it involves a case in which a proposition (the proposition that $p$ ) is embedded within a more complex proposition (the proposition that not- $p$ ). Spinoza and James do not talk about such cases, but if conceiving a 
proposition (grasping it, in Frege's lingo) is imagining it to be true, and if one cannot grasp a complex proposition without grasping the propositions that are its constituents, then whoever grasps or comprehends a complex proposition must go through a stage of imagining the constituent propositions to be true, that is, through a stage of temporally accepting these propositions. ${ }^{19}$ This generalizes, beyond the special case of negation, to all complex propositions. Not only does understanding a denial require the initial comprehension (hence the temporary acceptance) of that which is being denied; understanding — for example - a disjunction similarly requires the initial comprehension (hence the temporary acceptance) of the disjuncts.

\section{Imagination, belief, and simulation}

The critical premiss in Gilbert's argument as I have reconstructed it is that according to which to understand a (simple) proposition is to imagine it to be true, or, rather, to imagine the type of situation that would make it true. The situation in question is represented as holding, and that is a form of temporary acceptance, similar in many ways to supposition. In supposing, we do as if a certain proposition was true; we temporally accept it to see what follows. Likewise, in comprehending a proposition, we temporally accept it and represent the situation it describes as holding.

This view raises several prima facie objections, which I am going to address in turn. First, one may object that it is a mistake to talk of imagination here: to understand a sentence one does not have to "visualize" the type of situation that would make it true understanding consists in knowing what type of situation that is. That, I believe, is very much a terminological issue. In a broad sense - the sense which is relevant to this debate imagination need not be visual, nor even perceptual. Currie and Ravenscroft characterize what they call "recreative imagination" as a state that simulates a more basic state which, following others, they call the "counterpart" of the recreative state. The counterpart in question may be a perceptual state such as vision, but it may also be an intellectual state such as belief, a state which is simulated when we suppose something to be true:

Imaginative projection involves the capacity to have (...) states that are not perceptions or beliefs or decisions or experiences of movement of one's body, but which are in various ways like those states - like them in ways that enable the states possessed through imagination to mimic and, relative to certain purposes, to substitute for perceptions, beliefs, decisions, and experiences of movements. These are what we are calling states of recreative imagination. (...) In general, when a form of recreative imagining is $X$-like, we say that it has state $X$ as its counterpart. (Currie and Ravenscroft 2002: 11)

In visualization, the counterpart of the imaginative state is visual perception, while in supposition the counterpart is belief or judgment. Whatever the counterpart, "A good way to describe the relation between a piece of imagining and its counterpart is to say that imagination simulates this other thing. That implies likeness, and asymmetric dependence" (Currie and Ravenscroft 2002: 49). (I will say more about the notion of simulation shortly.)

\footnotetext{
${ }^{19}$ As Gregory Currie objected to me, I started with Gilbert's radical position, according to which to understand a proposition is already to believe it (at least temporarily), and am now shifting to the arguably weaker view that to understand a proposition is to imagine it to be true. This shift, from acceptance as belief to acceptance as imagination, must be justified, he says. I agree with Currie that the relation between belief and imagination needs to be clarified, and I will attempt to provide such clarification in section 6.
} 
The second potential objection targets the analogy with supposition. According to the objection, the state of temporary acceptance Gilbert talks about is something that happens to the subject when she understands an utterance, rather than a piece of behaviour she intentionally engages in, as when she pretends or makes a supposition. Supposition, perhaps, can construed as a type of "mental pretense" (Currie 1995a: 151; Goldman 2006: 47), but the notion of pretense - a type of activity - seems wholly inappropriate as a characterization of the state of linguistic understanding.

The objection is well taken, but the notion of imagination at stake applies more broadly than that of pretense. Pretending is necessarily intentional, but imagining may or may not be something one does intentionally. ${ }^{20}$ In the relevant cases (language understanding), imagining the situation that would make the sentence true is something that is automatically triggered by the linguistic signal; it is something that happens to the subject, indeed. In the case of supposition, however, imagining that $p$ is something we do intentionally: we imagine that $p$ to see what follows - we deliberately put ourselves in a state of mind of propositional imagining that simulates belief. The same thing holds for perceptual imagination. Goldman mentions cases in which the subject deliberately engages in visualisation in order to answer a question. ${ }^{21}$ I conclude that one should distinguish imagining as an activity, something one does, and imagining as a state. The former consists in intentionally bringing about the latter. While pretense and supposition (itself a kind of pretense) are imaginative activities, that is admittedly not the case for the sort of imagination that is at work when we process discourse (or, for that matter, when we watch a movie). ${ }^{22}$ Still, the notion of simulation applies. As Currie emphasizes,

One rather startling implication of the assimilation of imagining to simulation is that imagining should not be thought as always and automatically a conscious or even an intentional action, since simulation, if it is to do the work ascribed to it by simulation theorists, is sometimes neither conscious nor intentional. (Currie 1995a: 162; see also Goldman 2006: 49)

The third objection I need to address invokes the alleged incoherence of the view I have sketched. On the one hand, the view says that the subject who understands a sentence embedded in a more complex sentence is in a primitive state of belief with respect to the content of the embedded sentence - she represents the state of affairs described by the sentence as holding. That state is temporary, but it is a credal state, with a judgmental or assertoric character. On the other hand, I described the state in question as an imagining: the subject imagines the relevant type of situation. But imaginings are not beliefs! As Kathleen Stock puts it,

Imagining is different from belief. Believing something is functionally tied to perceptual inputs, other mental states, and behavioural outputs, in a way that merely imagining is not... If I believe something, normally I do so on the basis of having taken in some evidence or reasons for it, or having been told it by someone I take to be reasonably authoritative on the matter. If I believe something, I am also disposed to

\footnotetext{
20 "We use words like 'play' and 'pretend' for deliberate, concerted (...) performances, whereas we are more ready to use words like 'fancy' and 'imagine' for those activities of make-believe into which people casually and even involuntary drift” (Ryle 1949: 250).

${ }^{21}$ Goldman 2006: 39. See also p. 149, where he speaks of the "deliberate construction of a mental state with (quasi-) visual character".

${ }^{22}$ Of course, we intentionally go to the movie, or listen to a story-teller; but that only means that we intentionally put ourselves in the right conditions for enjoying an externally-induced state of imagination.
} 
feed the belief in a potentially unrestricted way into inferences with other beliefs. (...) Additionally, if I believe something, I shall be disposed to act upon that belief. (...) None of these things are true of imagining something. (Stock 2017: 20)

There is a sense in which imagining (what Stock calls "merely imagining") is not believing, indeed; it is not belief in the full-bodied sense. But there is also a sense in which imagining that $p$ is a credal state - a state akin to belief, as Gilbert argues. Remember that Gilbert distinguishes between two levels of acceptance. The functional difference Stock emphasizes is a difference between imagining and believing in the full-bodied sense. Belief in the full-bodied sense is what I referred to earlier as all-things-considered acceptance. ${ }^{23}$ Like rejection, all-things-considered acceptance belongs to the second of the two levels Gilbert distinguishes. At the first level, however, we find another form of acceptance, namely "basic" acceptance - the form of acceptance that cannot be dissociated from understanding. ${ }^{24}$ When the sentence whose content is entertained is embedded under "it is not the case that", or when it is part of a fictional text, the content which is temporally accepted at the first level as part of understanding is rejected at the second level and does not give rise to full-bodied belief. The judgmental/assertoric component constitutive of basic acceptance is cancelled at the second level: that is the process Gilbert describes as "unacceptance". The state of affairs which the sentence describes is still represented as holding, at the basic level, but that representation itself is tagged as untrue or as fictional. ${ }^{25}$ Tagging the representation in this way, at the second level, cancels its doxastic force by severing some of its connections to behavioural output and to the rest of the doxastic system. This is the operation known as "decoupling", a term that originates in Leslie's work on pretend play in children (Leslie 1987). Decoupling is known to play a key role in simulative activites such as fiction (reading novels, watching movies, etc.), planning, mindreading (attitude ascription), pretend play, and hypothetical reasoning, to mention only the most salient cases. ${ }^{26}$

The important point is that "mere imaginings" are the states that result from decoupling: through decoupling, the belief that is present at the basic level is "transmuted" into a state with a different functional profile. As Currie puts it,

Believing that it will rain has certain connections to perception and behaviour which, if they are severed, transmutes the belief into a case of imagining that it will rain. (Currie 1995b: 149)

Still, in the absence of decoupling, which cancels doxastic force, the state would be a belief in the full-bodied sense. Moreover, even when the doxastic force $i s$ cancelled and the state is transmuted into a mere imagining, it retains many of the signature characteristics of the belief it results from. As Weinberg and Meskin emphasize, after many others,

The imagination interacts with our ordinary inferential systems in much the same way as does the belief system. The patterns of reasoning in which children engage, while in

\footnotetext{
${ }^{23}$ This is my terminology, not Gilbert's. Gilbert talks of "certified" acceptance.

${ }^{24}$ The distinction between two levels of acceptance is paralleled by a distinction between two notions of imagination (a first-level and a second-level notion): see Recanati forthcoming $a$, section 3 .

${ }^{25}$ Of course there are other possible "tags" than these two. For example, when one ascribes a belief to someone, one cannot but entertain the content of the belief, but the content in question is indexed to the person in question, i.e. tagged as something which that person believes.

${ }^{26}$ Cosmides and Tooby argue that decoupling plays an even more central role in human cognition, by enabling "the use of contingent information for the regulation of improvised behavior that is successfully tailored to local conditions" (Cosmides and Tooby 2000: 53).
} 
the context of pretense, mirrors their reasoning in ordinary (i.e. non-imaginative) contexts. And this point can be supported by careful observation of the workings of ordinary fictions, which rely heavily on the capacity of consumers to make inferences in the context of their fiction-guided imaginings. (Weinberg and Meskin 2006: 18081)

Thus, despite all the functional differences between believing and merely imagining listed by Stock in the passage I quoted, imagining that $p$ still is

belief like in respect of inferential role: imagining that $\mathrm{P}$ leads to new imaginings in the way that believing $\mathrm{P}$ would lead to new beliefs. Beliefs also enter into practical inferences, where they combine with desires to produce decisions. Imaginative projections can (...) involve the recreation of practical inference: we imagine ourselves in this situation and then, in imagination, we decide to do something. (Currie and Ravenscroft 2002: 19-20)

Likewise, fictional imaginings give rise to affects, though mitigated by the knowledge that the situation they represent is imaginary. The same thing can be said about mindreading: when we put ourselves in some other person's shoes, for the purposes of empathetic understanding or for predicting their behaviour, we can simulate their feelings (Kahneman and Tversky 1982), that is, feel as they do or as they would, though our feelings in such cases are only feelings by proxy, much attenuated by the knowledge that the imagined predicament is that of another person.

The notion of simulation is meant to capture both the similarities and the differences between the imaginative state (i.e. the state that results from decoupling) and its full-bodied counterpart (the same state, without decoupling). Simulation is understood as a redeployment of the mental capacity that is being simulated. Because it is the same mental capacity that is redeployed, the patterns of similarity are explained. As for the functional differences, they are explained by the operation of decoupling. For example the inferential connections to other beliefs are not exploited in an unrestricted manner - as in the case of full-bodied beliefs but in a restricted manner corresponding to the idea that the beliefs that are merely simulated are "quarantined" (Leslie 1987) and do not freely interact with the rest of the subject's belief system (the full-bodied beliefs). ${ }^{27}$

The last objection I need to consider is one I fully endorse. It targets Gilbert's quasichronological interpretation of the relation between the basic level and the second level. This interpretation is apparent in passages like the following:

Unacceptance is a secondary psychological act in which the initial accepting that invariably accompanies comprehension is subsequently undone. Disbelief is (...) a deliberate revision of belief. (Gilbert 1991: 108; emphasis mine)

Spelling out the objection will help me address Currie's worry about the two possible interpretations of the notion of temporary acceptance (temporary acceptance as belief and temporary acceptance as imagination). ${ }^{28}$

\footnotetext{
27 "We may (...) think of quarantining in terms of a membrane that permits only one-way traffic: knowledge from the ordinary conceptual system can penetrate into the representations that govern pretend, but knowledge contained within the pretend system cannot travel in the reverse direction - it cannot alter the child's ordinary conceptual system of how things really are in the world" (Harris 1995: 172).

${ }^{28}$ see footnote 19 .
} 
Pace Gilbert, cancellation of acceptance (what he calls "unacceptance") need not take place "after" acceptance in a chronological sense. The precedence relation is logical, not chronological. Unacceptance comes "after" acceptance in the sense that it involves an operation (tagging-and-decoupling) that operates on, i.e. takes as input, a credal state of primitive acceptance; a state which is belief-like but which that very operation transmutes into a mere imagining. But the input state in question need not be tokened before it undergoes tagging-and-decoupling.

When one reads a piece of fiction, one knows in advance - even before entertaining them - that the propositions in the book are fictional and unworthy of all-things-considered acceptance. We entertain these propositions while knowing full well that they are fictional. This is different from first believing something (in the full-bodied sense) and then - possibly after only a very short time - revising one's belief. Imagine someone who suddenly sees (or takes herself to see) her long-dead spouse standing in front of her. That person cannot help but form the belief that her spouse is in front of her. That person will revise her belief very rapidly, as soon as she realizes that this is impossible and that the person in front of her must be a look-alike (possibly a twin). Here the short-lived state of temporary acceptance of the proposition that her spouse is in front of her can be described as a state of belief in the fullbodied sense. After revision, the belief will be modified and replaced by the belief that $i t$ looks as if her spouse is standing in front of her. In other words, the basic level representation of her spouse standing in front of her will be tagged (as a mere perceptual appearance) and decoupled. But in the case of fiction, tagging-and-decoupling takes place from the start: at no point does one believe, in the full-bodied sense, the things one reads in a novel (unless one mistakes the novel for a piece of non-fiction). It follows that, in the case of fiction and many similar cases, the state of acceptance the subject is in at the basic level is not really belief not even temporary belief. It is the simulation of belief, i.e. a state of imagination, from the start.

\section{Conclusion}

I have proposed that all the cases in which a proposition is said to be "merely entertained" are actually cases in which a "forceful" act of assertion or judgment, or a "forceful" state of belief, is simulated. This applies not only to cases like fiction, irony, or supposition, but also to the cases in which a proposition is entertained in the course of entertaining a more complex proposition of which it is a part. The notion of simulation I have used is the same one which simulation theory appeals to in connection with activities such as fiction (reading novels, watching movies, etc.), planning, mindreading, pretend play, and hypothetical reasoning. If this is right, then, as I suggested in an earlier paper, the capacity to think complex thoughts itself depends upon the capacity to simulate.

\section{References}

Bergson, H. (1907) L'Evolution Créatrice. Paris: Alcan. Breckenridge, W. and Magidor, O. (2012) Arbitrary Reference. Philosophical Studies 158: 377-400.

Castañeda, H.N (1975) Thinking and Doing. Dordrecht: Reidel.

Clark, H. (1996) Using Language. Cambridge: Cambridge University Press.

\footnotetext{
* I am indebted to Gregory Currie, Peter Hanks, Michael Schmitz and Merel Semeijn for discussion and comments.
} 
Clark, H., \& Gerrig, R. (1984). On the Pretense Theory of Irony. Journal of Experimental Psychology: General 113: 121-6.

Cosmides, L. and Tooby, J. (2000) Consider the Source : The Evolution of Adaptations for Decoupling and Metarepresentation. In D. Sperber (ed.) Metarepresentation : A

Multidisciplinary Perspective, 53-115. Oxford : Oxford University Press.

Currie, G. (1987) Remarks on Frege's Conception of Inference. Notre Dame Journal of

Formal Logic 28: 55-68.

Currie, G. (1995a) Imagination and Simulation: Aesthetics Meets Cognitive Science. In M.

Davis and T. Stone (eds.), 151-69.

Currie, G. (1995b) Image and Mind: Film, Philosophy, and Cognitive Science. Cambridge:

Cambridge University Press.

Currie, G. (2006) Why Irony is Pretence. In S. Nichols (ed.), 111-33.

Currie, G. and Ravenscroft, I. (2002) Recreative Minds. Oxford: Clarendon Press.

Davies, M., \& Stone, T. (eds.) (1995) Mental simulation. Oxford: Blackwell.

Donato Rodriguez, X. de (2016) Meinong's Theory of Assumptions and its Relevance for

Scientific Contexts. In A. Antonelli and M. David (eds.), Existence, Fiction, Assumption, 14173. Berlin: De Gruyter.

Ducrot, O. (1984) Le dire et le dit. Paris: Editions de Minuit.

Dummett, M. (1973) Frege : Philosophy of language. London: Duckworth.

Frege, G. (1984) Collected Papers on Mathematics, Logic, and Philosophy, ed. B.

McGuinness. Oxford: Oxford University Press.

Gentzen, G. (1969) Investigations into Logical Deduction. In M.E. Szabo (ed.), The Collected

Papers of Gerhard Gentzen, 405 - 31. Amsterdam: North-Holland.

Gilbert, D. (1991) How Mental Systems Believe. American Psychologist 46: 101-19.

Goldman, A. (2006) Simulating Minds: The Philosophy, Psychology, and Neuroscience of

Mindreading. New York: Oxford University Press.

Grice, P. (1989) Studies in the Way of Words. Cambridge, MA: Harvard University Press.

Hanks, P. (2007) The Content-Force Distinction. Philosophical Studies 134:141-64.

Hanks, P. (2011) Structured Propositions as Types. Mind $120: 11-52$.

Hanks, P. (2015) Propositional Content. Oxford : Oxford University Press.

Hanks, P. (2019) On Cancellation. Synthese 196 : 1385-402.

Harris, P. (1995) Imagining and Pretending. In M. Davies and T. Stone (eds), 170-84.

Hom, C. and Schwartz, J. (2013) Unity and the Frege-Geach Problem. Philosophical Studies $163: 15-24$.

James, W. (1890) The Principles of Psychology, vol. 2. New York: Henry Holt and C ${ }^{\circ}$ Johnson-Laird, P. (1986) How is Meaning Mentally Represented? Versus 44/45: 99-118.

Kahneman, D. and Tversky, A. (1982) The Simulation Heuristics. In D. Kahneman, P. Slovic and A. Tversky, Judgments under uncertainty: Heuristics and Biases, 201-8. Cambridge:

Cambridge University Press.

Kripke, S. (2013) Reference and Existence. Oxford : Oxford University Press.

Leslie, A. (1987). Pretense and Representation: The Origins of "Theory of Mind".

Psychological Review 94 : 412-26.

Lewis, D. (1978) Truth in Fiction. American Philosophical Quarterly 15: 37-46.

Meinong, A. (1983) On Assumptions, ed. J. Heanue. Berkeley: University of California Press.

Nichols, S. (ed.) (2006) The Architecture of the Imagination. Oxford: Clarendon Press.

Prawitz, D. (1965) Natural Deduction: A Proof-Theoretical Study. Stockholm: Almqvist \&

Wiksell.

Recanati, F. (1987) Meaning and Force. Cambridge : Cambridge University Press.

Recanati, F. (2019) Force Cancellation. Synthese 196: 1403-24. 
Recanati, F. (forthcoming a) Fictional Reference as Simulation. In E. Maier and A. Stokke (eds.) The Language of Fiction. Oxford: Oxford University Press.

Recanati, F. (forthcoming $b$ ) Understanding Force Cancellation. Inquiry, special issue on The Act-Type Theory of Propositional Content (A. Fernández and P. Hanks eds.).

Reiland, I. (2013) Propositional Attitudes and Mental Acts. Thought 1: 239-45.

Rips, L. and Marcus, S. (1977) Supposition and the Analysis of Conditional Sentences. In M.A. Just and P.A. Carpenter (eds.) Cognitive Processes in Comprehension, 185-220.

Hillsdale: Erlbaum.

Ryle, G. (1949) The Concept of Mind. London: Hutchinson.

Schmitz, M. (2019) Force, Content, and the Varieties of Subject. Language and

Communication 69: 115-29.

Schmitz, M. (forthcoming) Questions, Content and the Varieties of Force.

Searle, J. (1969) Speech Acts. Cambridge: Cambridge University Press.

Searle, J. (1975) The Logical Status of Fictional Discourse. New Literary History 6: 319-32.

Sigwart, C. (1904) Logik (3rd ed.). Tübingen: Mohr.

Sperber, D. and Wilson, D. (1981) Irony and the Use/Mention Distinction. In P. Cole (ed.), Radical Pragmatics, 295-318. London: Academic Press.

Stock, K. (2017) Only Imagine. Oxford: Oxford University Press;

Strawson, P. (2000) Entity and Identity, and Other Essays. Oxford : Clarendon Press.

Walton, K. (1990) Mimesis as Make-Believe. Cambridge : Harvard University Press.

Weinberg, J. and Meskin, A. (2006) Puzzling over the Imagination: Philosophical Problems, Architectural Solutions. In Nichols (ed.), 175-202.

Williamson, T. (2020) Suppose and Tell: The Semantics and Heuristics of Conditionals.

Oxford: Oxford University Press.

Wilson, D., \& Sperber, D. (2012) Meaning and Relevance. Cambridge: Cambridge University Press. 